Open Access

\title{
Lignocellulose-converting enzyme activity profiles correlate with molecular systematics and phylogeny grouping in the incoherent genus Phlebia (Polyporales, Basidiomycota)
}

Jaana Kuuskeri ${ }^{1 *}$, Miia R. Mäkelä ${ }^{1}$, Jarkko Isotalo², llona Oksanen ${ }^{1}$ and Taina Lundell ${ }^{1}$

\begin{abstract}
Background: The fungal genus Phlebia consists of a number of species that are significant in wood decay. Biotechnological potential of a few species for enzyme production and degradation of lignin and pollutants has been previously studied, when most of the species of this genus are unknown. Therefore, we carried out a wider study on biochemistry and systematics of Phlebia species.
\end{abstract}

Methods: Isolates belonging to the genus Phlebia were subjected to four-gene sequence analysis in order to clarify their phylogenetic placement at species level and evolutionary relationships of the genus among phlebioid Polyporales. rRNA-encoding (5.8S, partial LSU) and two protein-encoding gene (gapdh, rpb2) sequences were adopted for the evolutionary analysis, and ITS sequences (ITS1 + 5.8S + ITS2) were aligned for in-depth species-level phylogeny. The 49 fungal isolates were cultivated on semi-solid milled spruce wood medium for 21 days in order to follow their production of extracellular lignocellulose-converting oxidoreductases and carbohydrate active enzymes.

Results: Four-gene phylogenetic analysis confirmed the polyphyletic nature of the genus Phlebia. Ten species-level subgroups were formed, and their lignocellulose-converting enzyme activity profiles coincided with the phylogenetic grouping. The highest enzyme activities for lignin modification (manganese peroxidase activity) were obtained for Phlebia radiata group, which supports our previous studies on the enzymology and gene expression of this species on lignocellulosic substrates.

Conclusions: Our study implies that there is a species-level connection of molecular systematics (genotype) to the efficiency in production of both lignocellulose-converting carbohydrate active enzymes and oxidoreductases (enzyme phenotype) on spruce wood. Thus, we may propose a similar phylogrouping approach for prediction of lignocellulose-converting enzyme phenotypes in new fungal species or genetically and biochemically less-studied isolates of the wood-decay Polyporales.

Keywords: White rot fungus, Wood decay, Lignocellulose, Lignin biodegradation, Oxidoreductases, Carbohydrate active enzymes, Molecular systematics, Multi-locus phylogeny, Phlebia, Polyporales, Basidiomycota

\footnotetext{
* Correspondence: jaana.kuuskeri@helsinki.fi

'Department of Food and Environmental Sciences, Division of Microbiology and Biotechnology, University of Helsinki, Viikki Biocenter 1, P.O.B. 56, FIN-00014 Helsinki, Finland

Full list of author information is available at the end of the article
} 


\section{Background}

Fungi of the phylum Basidiomycota have an important role in the global carbon cycle due to their ability to decompose plant biomass that is the richest carbon source on earth. Basidiomycota class Agaricomycetes, in particular the order Polyporales, includes species which are efficient decomposers of wood and other plant biomass, and are able to activate and degrade lignin [1, 2]. The ability to decompose polymeric wood components, that is cellulose, hemicellulose and lignin, requires sets of carbohydrate active enzymes (CAZymes), and oxidoreductases such as peroxidases and laccases [3-5].

The fungal genus Phlebia includes several ligninmodifying white rot species which have a high potential for forest-based biotechnology, biopulping, production of lignocellulose-active enzymes and conversion of lignin-derived compounds and xenobiotics [6-15]. Taxonomically, the genus Phlebia is positioned to the Polyporales phlebioid clade and to the family Meruliaceae [16-20]. The phlebioid clade includes mainly corticioid basidiocarp-forming species, and the clade consists of seven family names including Phlebiaceae originally given by Jülich in 1981 [21]. The genus Phlebia has a multitude of species [20, 21] with 203 and 220 taxons recorded in MycoBank (http://www.mycobank.org/) and Index Fungorum (http://www.indexfungorum.org), respectively (August 2015). Phlebia has several synonym genera - Merulius, Mycoaciella and Mycoacia [22, 23].

The type species Phlebia radiata Fr. [24] is widely distributed in North America and Europe [25] and has been a subject of genetic and biochemical studies [26-30]. P. radiata is a white rot fungus which efficiently degrades lignin in softwood and hardwood [31, 32], depolymerizes milled pine wood [33], mineralizes ${ }^{14} \mathrm{C}$-labelled synthetic lignin (DHP) to carbon dioxide [34, 35], and efficiently produces a versatile set of lignin-modifying oxidoreductases (class II peroxidases and laccase) [26, 28, 30, 35-38]. In addition to $P$. radiata, research has focussed on a few other species of the genus, e.g. P. tremellosa, P. brevispora, $P$. ochraceofulva and P. lindtneri, in regard to physiology and potential for bioconversion of plant biomass [39-45]. According to genome sequencing of the species $P$. brevispora $[2,4,21]$ and $P$. radiata (ongoing) [29], there is a versatile repertoire of genes encoding lignin-modifying and other lignocellulose-converting oxidoreductases, and multiple CAZymes. However, while genomic data may predict the number of genes and potential functions of the extracellular lignocellulose-converting enzymes in fungal species, protein secretion and biochemical enzyme activities need to be verified by proteomics and activity assays, respectively. This is particularly important on natural growth substrates such as wood. Therefore, we performed lignocellulose-converting enzyme activity profiling of 49 Phlebia species on wood cultures. The production of lignocellulose-converting enzyme activities were compared with the molecular taxonomy, in order to find out if the enzyme phenotypes of the species groups were determined by their evolutionary proximity and genotype characters.

Our second aim was to deepen the taxonomic knowledge of the phlebioid clade in Polyporales and study the genetic diversity of Phlebia by adopting rRNA-encoding (SSU and LSU) and two cellular core protein-encoding genes - glyceraldehyde phosphate dehydrogenase (gapdh) and nuclear RNA polymerase II (rpb2). The internal transcribed spacer (ITS) sequence has been selected for fungal barcoding and identification [46], giving adequate information for fungal isolate level molecular taxonomy and definition of species. Recently, extensive ITS sequence analysis of phanerochaetoid taxa in the phlebioid clade enlightened the complex phylogeny of this clade [20] and by focusing on the Phlebia clade, our study even deepens the understanding of this clade. In our study, statistical and clustering analyses of the Phlebia genotype groups with their enzyme activity production profiles demonstrated that the enzyme phenotypes correlated with the species group genotypes. Thus, for the diverse Phlebia species, there is a strong connection between the genotype and their CAZyme and lignin-modifying oxidoreductase activity profiles on a natural-like, wood-supplemented growth medium.

\section{Results}

\section{Molecular identification of Phlebia isolates}

Results obtained from ITS1-5.8S-ITS2 PCR and sequencing of the Phlebia isolates confirmed their earlier identification results, which were mostly based on their basidiocarp morphological features, with a few exceptions (Additional file 1: Table S1). Most of the FBCC (University of Helsinki Fungal Biotechnology Culture Collection) isolates previously identified to the species $P$. radiata were correctly confirmed including 14 isolates which were $100 \%$ identical according to their complete ITS sequences (Fig. 1). The only exceptions were the isolates FBCC4 and FBCC345, which were over $99 \%$ identical to the species $P$. acerina (Additional file 1: Table S1). In addition, the phylogenetic maximum likelihood analysis strongly supported positioning of the two isolates in the P. acerina branch (bootstrap value 97, Fig. 1) and thereby, these isolates were re-named $P$. acerina at the species level in this study.

Also, the isolates FBCC421 and FBCC426 were renamed $P$. centrifuga and $P$. subserialis, respectively, according to their ITS-sequence identity $(99.0 \%$ and $99.8 \%)$ in comparison to taxon reference sequences (Additional file 1: Table S1) and support from high node bootstrap values (100 and 100) (Fig. 1 and Additional file 2: Figure S1a). Considering P. subserialis, our isolate 


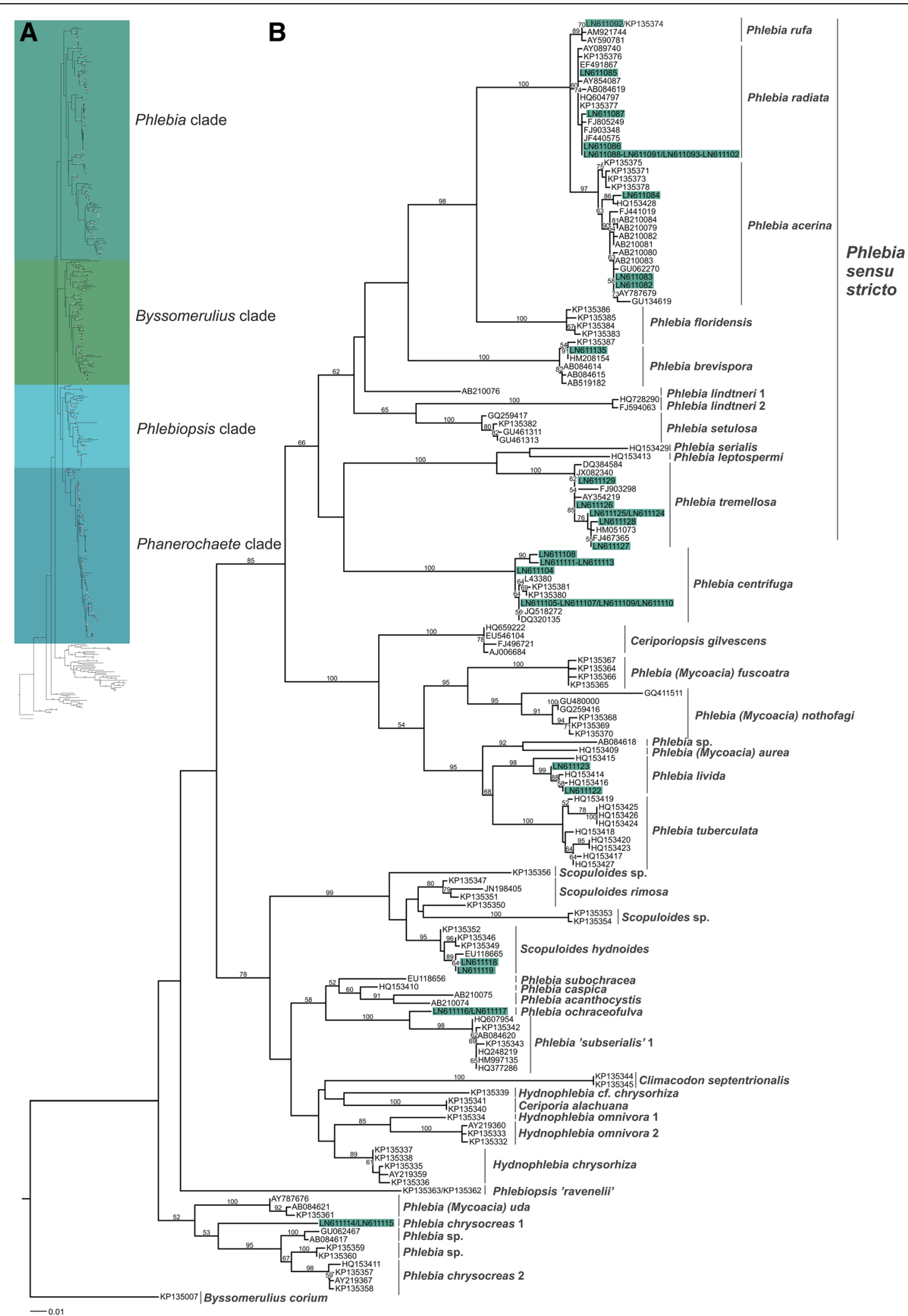

Fig. 1 (See legend on next page.) 
(See figure on previous page.)

Fig. 1 Maximum likelihood trees of the phlebioid clade and Phlebia clade of Polyporales based on ITS1-5.8S-ITS2 sequences. (a) Maximum likelihood tree illustrating the separation of four clades (Phlebia, Byssomerulius, Phlebiopsis and Phanerochaete) in the phlebioid clade. For the tree, 481 ITS sequences were aligned and phylogenetical analysis was performed using RAxML v. 7.2.8. and 100x bootstrapping. (b) Maximum likelihood analysis of ITS1-5.8S-ITS2 sequences from the Phlebia clade. Fungi of this study (shaded in green, ITS accession numbers are presented in Table 1) are compared with related taxons with sequences retrieved from NCBI (http://www.ncbi.nlm.nih.gov/) database. Bootstrap values (100 replications) higher than 50 \% are indicated for the nodes. Quotation marks represent uncertain identification or provisional names suggested [20]. An ITS sequence of Byssomerulius corium was used as an outgroup. Scale bar represents 0.01 nucleotide substitutions per position

FBCC426 and one reference sequence were positioned far away from Phlebia species into the Phanerochaete clade. Our ITS-sequencing and phylogenetic analyses were unable to confirm the previous identification for three isolates of the 54 studied. Isolate FBCC427 (initially $P$. subserialis) was positioned in the Phlebiopsis clade but distant from Phlebiopsis, Rhizochaete and Phaeophlebiopsis (Additional file 2: Figure S1b). Isolate FBCC296 (initially P. albida) was distantly related to the Phlebia clade and was situated in the Phanerochaete clade. However, more information is apparently needed to confirm the species level taxonomy, and therefore, these isolates were not yet given definite identities or taxon names, and are thus depicted Phlebia sp. isolates (Additional file 1: Table S1).

\section{ITS phylogeny}

An ITS sequence dataset was generated for phylogenetic analyses of the Polyporales phlebioid clade by including reference sequences retrieved from NCBI GenBank and the sequences of this study. Altogether 481 ITS sequences were included in the maximum likelihood (ML) phylogram (Fig. 1a), and 156 sequences were positioned in the Phlebia clade (Fig. 1b). The phylogenetic analyses resulted in three major clades in the phlebioid clade, which were named according to Floudas and Hibbet [20] as Phlebia, Byssomerulius and Phanerochaete clades. Similarly as in the recent study [20], the Phanerochaete clade was divided into Phlebiopsis and Phanerochaete clades.

According to the ITS phylogeny, genus Phlebia produced no single taxonomic cluster (Fig. 1). While Phlebia species are widely distributed in the ITS tree, the Phlebia sensu stricto species form one uniform core group, which includes the type species $P$. radiata (Fig. 1b). The three species $P$. radiata, $P$. acerina and $P$. rufa are very closely related forming a distinct branch (bootstrap value 100) in the Phlebia clade. In addition, Phlebia sensu stricto includes the species P. floridensis, P. brevispora, P. lindtneri, P. setulosa, P. serialis, P. leptospermi and $P$. tremellosa. It is noteworthy that the Phlebia clade includes a number of isolates that were identified to the genera Ceriporiopsis, Scopuloides, Climacodon, Phlebiopsis, Ceriporia and Hydnophlebia (Fig. 1b).
Furthermore, the species P. unica, P. firma, and two isolates of $P$. subserialis were clearly separated from the Phlebia clade and were positioned in Phanerochaete or Phlebiopsis clades (Additional file 2: Figure S1). Three isolates without a previous species-level identity and thus named Phlebia sp. were similarly positioned outside the Phlebia clade.

\section{Four-gene phylogeny}

According to the four-gene multilocus phylogeny analysis, Phlebia isolates were divided into ten phylogroups (Fig. 2a, Table 1). Statistical analyses of the enzyme activity data were based on this grouping except for P. brevispora due to only one isolate cultivated for enzyme profiling. The first phylogroup included isolates of the species $P$. radiata and $P$. rufa (Fig. 2a). The wellsupported sister lineage to this phylogroup was the $P$. acerina branch consisting of three isolates. According to the four-gene phylogeny, $P$. tremellosa clearly deviated from the $P$. radiata and $P$. acerina species groups with $100 \%$ branching support (Fig. 2a). The species P. brevispora and $P$. livida, as well as $P$. hydnoides, $P$. chrysocreas and $P$. ochraceofulva all branched as sister lineages forming distinct species clusters or clades, and were therefore treated as separate phylogroups in the statistical enzyme-phenotype analyses.

Isolates of $P$. radiata, $P$. tremellosa, $P$. centrifuga and P. subserialis also diverged at the species level (Fig. 2a). However, the $P$. subserialis group was formed by only two isolates, and more noteworthy, the isolate FBCC426 is the nearest related to species of Phanerochaete $(P$. chrysosporium and P. carnosa, bootstrap value $100 \%)$. Moreover, the two Phanerochaete species, Phlebia subserialis, and the isolates Phlebia sp. FBCC296 and FBCC427 were positioned far out from the Phlebia sensu stricto, and in fact, these isolates were the most related to the species Phlebiopsis gigantea and Bjerkandera adusta (Fig. 2a).

Presence or absence of introns, intron positioning and intron length varied in Phlebia gapdh genes with respect to the species grouping (Fig. $2 \mathrm{~b}$ ). The $P$. radiata and $P$. acerina phylogroups had similar gapdh exon-intron structures and length of the sequenced region. P. tremellosa and $P$. hydnoides phylogroups were similarly uniform. Other phylogroups showed variable sizes of gapdh 


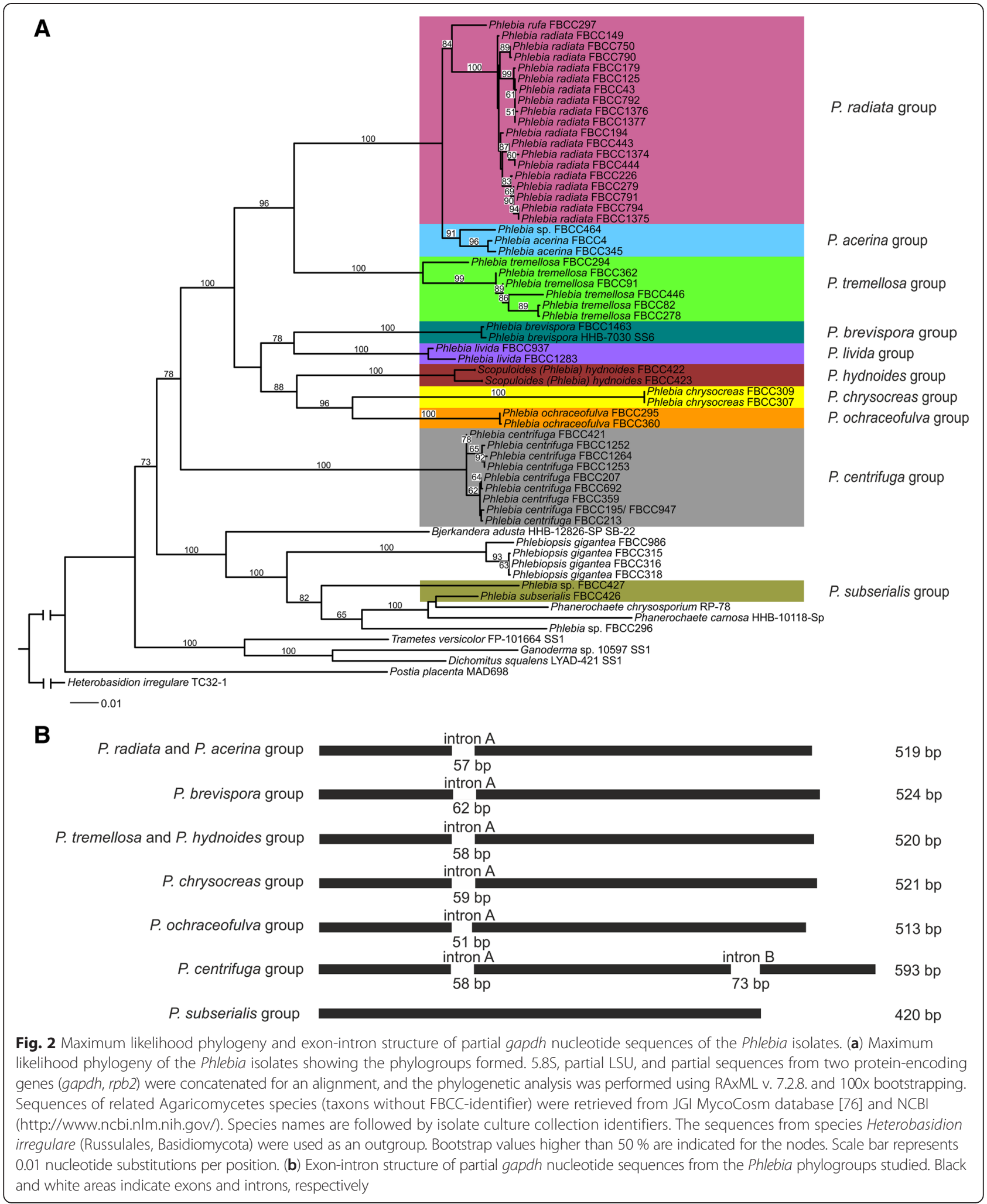

PCR products due to differences in intron length and positioning. All $P$. centrifuga gapdh sequences had a unique intron $\mathrm{B}$, whereas isolate $\mathrm{FBCC} 427$ from the $P$. subserialis group as well as Phlebia sp. FBCC296 and all Phlebiopsis gigantea isolates lacked both introns A and B. With the gapdh primers used, no PCR-product was 
Table 1 Fungal isolates of this study

\begin{tabular}{|c|c|c|c|c|c|c|}
\hline Group name ${ }^{a}$ & $\begin{array}{l}\text { Fungal Biotechnological } \\
\text { Culture Collection } \\
\text { identifier }\end{array}$ & Identity $^{b}$ & Site of origin & $\begin{array}{l}\text { Natural } \\
\text { substrate }^{c}\end{array}$ & $\begin{array}{l}\text { ITS Accession } \\
\text { number }\end{array}$ & $\begin{array}{l}\text { Isolate number } \\
\text { used in Figs. } 4 \\
\text { and } 5\end{array}$ \\
\hline \multirow[t]{19}{*}{ P. radiata group } & 43 & Phlebia radiata & Finland; Vantaa & $\mathrm{D}$ & LN611085 & 1 \\
\hline & 297 & Phlebia rufa & Sweden & & LN611092 & 2 \\
\hline & 125 & Phlebia radiata & Finland; Lieksa & $\mathrm{D}$ & LN611086 & 3 \\
\hline & 149 & Phlebia radiata & Finland; Ruovesi & D & LN611087 & 4 \\
\hline & 179 & Phlebia radiata & Finland; Lammi & $\mathrm{D}$ & LN611088 & 5 \\
\hline & 194 & Phlebia radiata & Finland; Sodankylä & $\mathrm{D}$ & LN611089 & 6 \\
\hline & 226 & Phlebia radiata & Finland; Kolari & D & LN611090 & 7 \\
\hline & 279 & Phlebia radiata & Sweden & & LN611091 & 8 \\
\hline & 443 & Phlebia radiata & UK & $\mathrm{D}$ & LN611093 & 9 \\
\hline & 444 & Phlebia radiata & France & & LN611094 & 10 \\
\hline & 750 & Phlebia radiata & Finland; Lammi & & LN611095 & 11 \\
\hline & 790 & Phlebia radiata & Finland; Ruovesi & D & LN611096 & 12 \\
\hline & 791 & Phlebia radiata & Finland; Ruovesi & $\mathrm{D}$ & LN611097 & 13 \\
\hline & 792 & Phlebia radiata & Finland; Ruovesi & $\mathrm{D}$ & LN611098 & 14 \\
\hline & 794 & Phlebia radiata & Finland; Ruovesi & $D$ & LN611099 & 15 \\
\hline & 1374 & Phlebia radiata & Finland; Lammi & $\mathrm{D}$ & LN611100 & 16 \\
\hline & 1375 & Phlebia radiata & Finland; Ruovesi & $\mathrm{D}$ & LN611101 & 17 \\
\hline & 1376 & Phlebia radiata & unknown & & LN611102 & 18 \\
\hline & 1377 & Phlebia radiata & unknown & & LN611103 & 19 \\
\hline \multirow[t]{3}{*}{ P. acerina group } & 4 & Phlebia acerina & unknown & & LN611082 & 20 \\
\hline & 345 & Phlebia acerina & Russia & & LN611083 & 21 \\
\hline & 464 & Phlebia sp. & Argentina; Bariloche & $\mathrm{D}$ & LN611084 & 22 \\
\hline P. brevispora group & 1463 & Phlebia brevispora & USA; Florida & & LN611135 & 23 \\
\hline \multirow[t]{6}{*}{ P. tremellosa group } & 82 & Phlebia tremellosa & Finland; Salo & $\mathrm{D}$ & LN611124 & 24 \\
\hline & 91 & Phlebia tremellosa & Finland; Perniö & $\mathrm{D}$ & LN611125 & 25 \\
\hline & 294 & Phlebia tremellosa & Canada & $\mathrm{D}$ & LN611127 & 26 \\
\hline & 362 & Phlebia tremellosa & Russia; Kavalerovo & $\mathrm{D}$ & LN611128 & 27 \\
\hline & 446 & Phlebia tremellosa & Netherlands & & LN611129 & 28 \\
\hline & 278 & Phlebia tremellosa & Sweden & & LN611126 & 29 \\
\hline \multirow[t]{2}{*}{ P. livida group } & 937 & Phlebia livida & Finland; Lammi & C & LN611122 & 30 \\
\hline & 1283 & Phlebia livida & Norway; Telemark & C & LN611123 & 31 \\
\hline \multirow[t]{2}{*}{ P. hydnoides group } & 423 & $\begin{array}{l}\text { Phlebia (Scopuloides) } \\
\text { hydnoides }\end{array}$ & $\begin{array}{l}\text { Belgium; Bois de } \\
\text { Matignolle }\end{array}$ & $\mathrm{D}$ & LN611119 & 32 \\
\hline & 422 & $\begin{array}{l}\text { Phlebia (Scopuloides) } \\
\text { hydnoides }\end{array}$ & France; Haute Savoie & & LN611118 & 33 \\
\hline \multirow[t]{2}{*}{ P. chrysocreas group } & 307 & Phlebia chrysocreas & unknown & & LN611114 & 34 \\
\hline & 309 & Phlebia chrysocreas & unknown & & LN611115 & 35 \\
\hline \multirow[t]{2}{*}{ P. ochraceofulva group } & 295 & Phlebia ochraceofulva & Sweden & & LN611116 & 36 \\
\hline & 360 & Phlebia ochraceofulva & Sweden & & LN611117 & 37 \\
\hline \multirow[t]{3}{*}{ P. centrifuga group } & 207 & Phlebia centrifuga & Finland; Kolari & C & LN611105 & 38 \\
\hline & 213 & Phlebia centrifuga & Finland; Aakenus & C & LN611106 & 39 \\
\hline & 195 & Phlebia centrifuga & Finland; Sodankylä & C & LN611104 & 40 \\
\hline
\end{tabular}


Table 1 Fungal isolates of this study (Continued)

\begin{tabular}{|c|c|c|c|c|c|c|}
\hline & 359 & Phlebia centrifuga & Sweden & & LN611107 & 41 \\
\hline & 692 & Phlebia centrifuga & Finland; Sodankylä & C & LN611109 & 42 \\
\hline & 947 & Phlebia centrifuga & Finland; Kolari & C & LN611110 & 43 \\
\hline & 1252 & Phlebia centrifuga & $\begin{array}{l}\text { Bulgaria; Rila } \\
\text { mountains }\end{array}$ & & LN611111 & 44 \\
\hline & 1253 & Phlebia centrifuga & $\begin{array}{l}\text { Bulgaria; Rila } \\
\text { mountains }\end{array}$ & & LN611112 & 45 \\
\hline & 1264 & Phlebia centrifuga & $\begin{array}{l}\text { Bulgaria; Rila } \\
\text { mountains }\end{array}$ & & LN611113 & 46 \\
\hline & 421 & Phlebia centrifuga & USA; Idaho & C & LN611108 & 47 \\
\hline \multirow[t]{2}{*}{ P. subserialis group } & 426 & Phlebia subserialis & France & & LN611120 & 48 \\
\hline & 427 & Phlebia sp. & France; Rhône & & LN611121 & 49 \\
\hline \multirow{5}{*}{$\begin{array}{l}\text { Species included in } \\
\text { phylogenetic study }\end{array}$} & 296 & Phlebia sp. & Sweden & & LN611130 & \\
\hline & 315 & Phlebiopsis gigantea & Sweden & & LN611131 & \\
\hline & 316 & Phlebiopsis gigantea & Sweden & & LN611132 & \\
\hline & 318 & Phlebiopsis gigantea & Sweden & & LN611133 & \\
\hline & 986 & Phlebiopsis gigantea & Finland; Kolari & C & LN611134 & \\
\hline
\end{tabular}

${ }^{a}$ Confirmed by ITS1-5.8S-ITS2 and LSU sequence similarity using nBLAST search. See details in Methods

${ }^{\mathrm{b}}$ The isolates were grouped based on ITS sequence similarity and phylogrouping based on phylogenetic analyses of concatenated SSU, partial LSU sequences, and partial sequences from two protein-encoding genes (gapdh, rpb2)

${ }^{\mathrm{c}} \mathrm{C}=$ Coniferous wood, $\mathrm{D}=$ Deciduous wood

obtained for the P. livida isolates, which leaves the question open whether this species group has a more variable gapdh gene structure than the other studied species. In general, exon-intron structure of the gapdh gene (Fig. 2b) was coherent with the multilocus sequence phylogeny and phylogrouping of Phlebia species.

Phylogenetic analyses conducted with either individual or contiguous ITS and partial LSU sequences, and respectively with individual or concatenated gapdh and $r p b 2$ sequences, resulted in evolutionary trees with slightly different topologies than was obtained with the four-gene phylogeny (Additional file 3: Figure S2, Additional file 4: Figure S3). Phylogenetic analyses based on ITS and gapdh sequences positioned $P$. brevispora near to $P$. radiata - P.acerina sister species, when the LSU and $r p b 2$ sequences were not able to confirm its evolutionary placement (Additional file 4: Figure S3). Our four-gene phylogeny also positioned $P$. brevispora closer to $P$. livida than to $P$. radiata. Positioning of $P$. livida as well as $P$. hydnoides was not supported by the protein-encoding sequences (Additional file 3: Figure S2b). Taken together, similar fungal speciesbased phylogroupings were observed in all evolutionary analyses.

\section{Fungal growth rates and activity normalization}

In order to test if the enzyme activities were influenced by the differences in fungal growth rates, we tried to estimate production of mycelium biomass (as mycelium dry weight) for each isolate and each culture flask in the end of cultivation. However, deviation of the dry weight values between the parallel cultures (three parallel culture flasks) was too divergent. This was probably due to wood sawdust particles that were attached to the mycelia. Instead, we measured the hyphal growth rate on malt agar plates for each isolate, and used these values $\left(\mathrm{cm} \mathrm{d}^{-1}\right)$ (Additional file 5: Figure S4f) to adjust the enzyme activity values $\left(\mu \mathrm{kat}^{-1}\right.$ ) of day 14 . This normalization resulted in fairly similar differences between the isolates and species groups that was observed with the non-normalized enzyme activities, except for a few isolates of $P$. centrifuga (see below).

\section{Production of enzyme activities}

During the 21 days of cultivation on semi-solid liquid medium with milled spruce as a carbon source, all the 49 Phlebia isolates produced lignocellulose-converting enzyme activities periodically (Fig. 3). When the enzyme activity patterns were investigated on the $14^{\text {th }}$ day of cultivation, differences between Phlebia phylogroups became apparent (Fig. 4). The $P$. radiata group produced the highest levels of oxidoreductase activities, that is laccase and manganese peroxidase ( $\mathrm{MnP}$ ) (up to 3.0 and $0.9 \mu \mathrm{kat} \mathrm{l}^{-1}$, respectively) (Fig. 4a, b). The highest laccase activity, $3.0 \mu \mathrm{kat} \mathrm{l}^{-1}$, was observed in the cultures of $P$. radiata $\mathrm{FBCC} 149$, whereas $P$. radiata FBCC125 produced the highest $\mathrm{MnP}$ activity $(0.9 \mu \mathrm{kat}$ $\left.\mathrm{l}^{-1}\right)$. Relatively high laccase and $\mathrm{MnP}$ activites were 

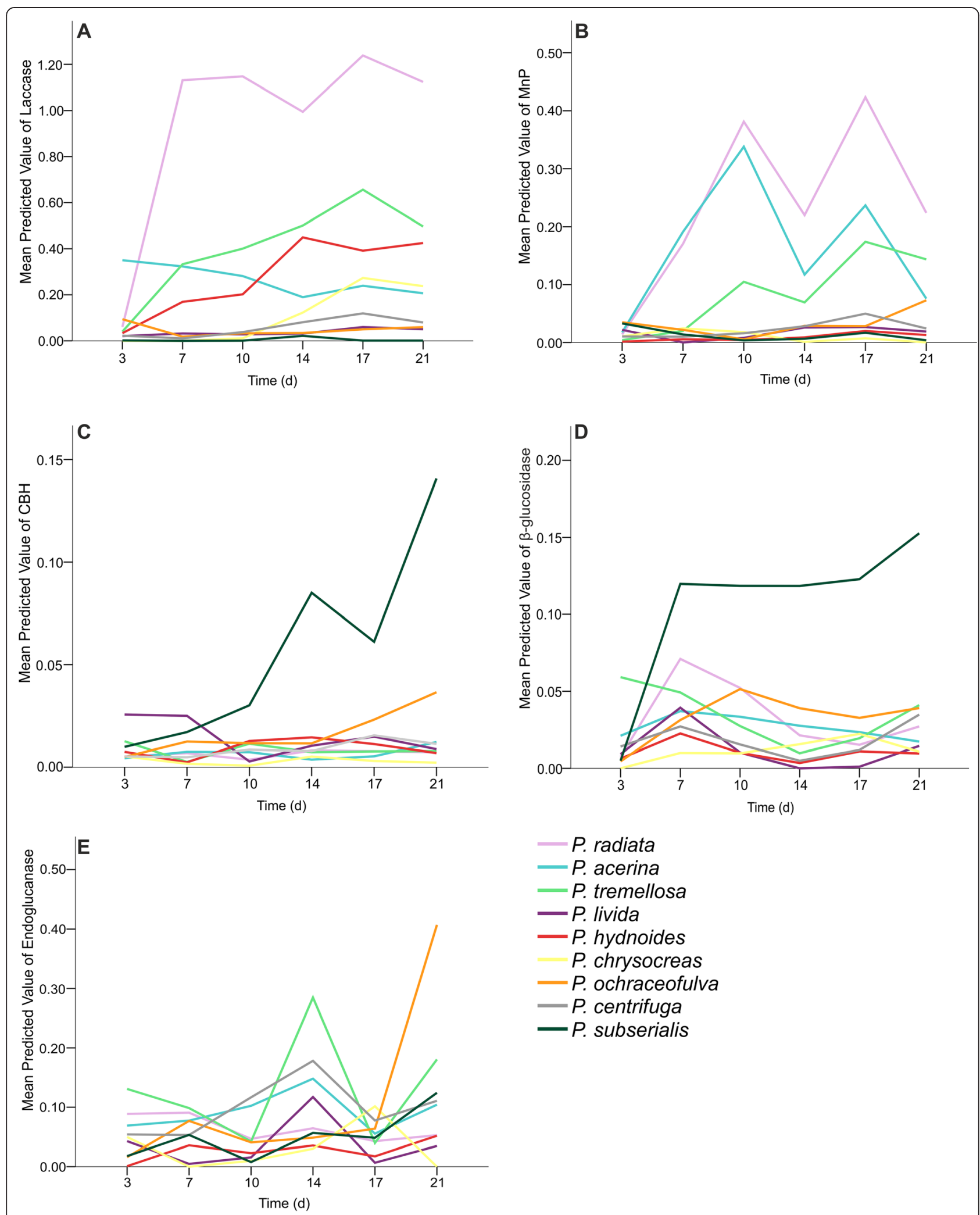

Fig. 3 Fitted values of enzyme activities of each phylogenetic group. Fitted values (mean predicted value) of (a) laccase (b) MnP (c) CBH (d) $\beta$-glucosidase and (e) endoglucanase activities of each phylogenetic group during 21 days of cultivation in semi-solid milled spruce cultures 


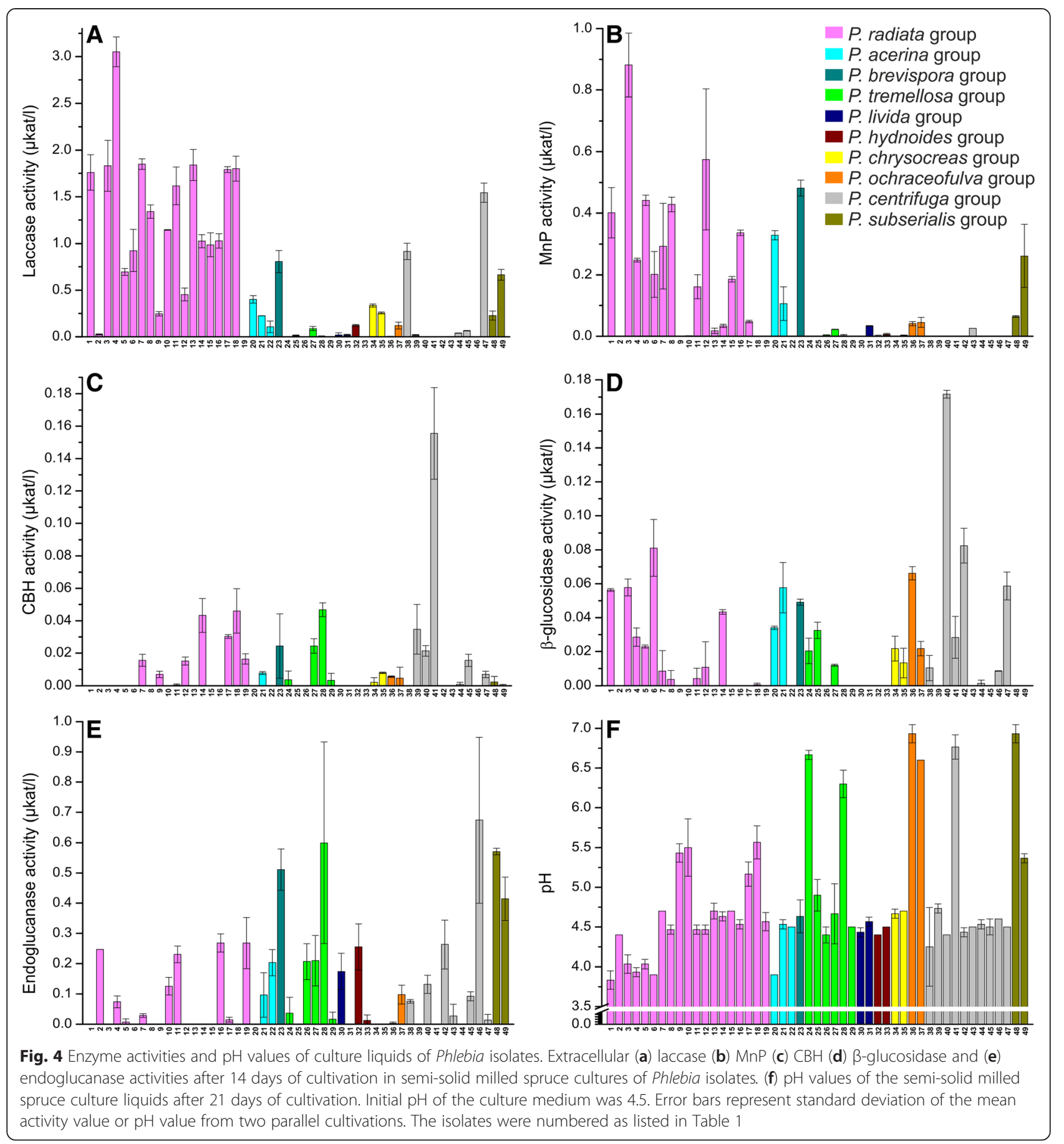

detected in the cultures of P. brevispora FBCC1463. Even though the overall production of laccase in the $P$. centrifuga phylogroup was moderate, one isolate (FBCC421) in this group attained similar activity levels (maximum $1.5 \mu \mathrm{kat}^{-1}$ ) as obtained in the $P$. radiata $P$. acerina phylogroups. However, with normalized laccase activities another isolate of $P$. centrifuga (FBCC207) demonstrated the highest production value on the day 14, which is due to its very slow hyphal growth rate (Additional file 5: Figures S4a, S4f). In the case of $\mathrm{MnP}$ activity, normalization of the data (on day 14) caused minor differences, with an exceptionally high value for one slow-growing isolate of $P$. centrifuga (FBCC947) (Additional file 5: Figures S4b, S4f).

In contrast to the lignin-modifying oxidoreductases, the activity production profiles of the hydrolytic CAZymes were more coherent within each phylogroup (Fig. 3), and less evident differences were detected in the 
CAZyme activity levels between the fungal isolates of each phylogroup (Fig. 4). Concerning cellulosedegrading enzyme activities, the highest level of endoglucanase activity was detected after two weeks for the isolates $P$. tremellosa, $P$. centrifuga and $P$. subserialis (Fig. 4e), peaking up to $0.7 \mu \mathrm{kat}^{-1}$ in the culture liquid of $P$. centrifuga FBCC1264. Cellobiohydrolase (CBH) activities in turn were marginal, and the highest values $\left(0.16 \mu \mathrm{kat}^{-1}\right)$ were observed for the P. centrifuga phylogroup (Fig. 4c), which was furthermore obvious with the normalized activity values (Additional file 5: Figure S4c). The highest $\beta$-glucosidase activity $\left(0.17 \mu \mathrm{kat}^{-1}\right)$ was also produced in the $P$. centrifuga phylogroup (Fig. 4d). Activities of $\beta$-glucosidase in $P$. radiata, $P$. acerina, $P$. brevispora, $P$. tremellosa and $P$. ochraceofulva phylogroups were at similar levels but isolate-level differences within each of the phylogroups were detected (Fig. 4d). When $\mathrm{CBH}$ activities were studied, the $P$. radiata species group shared similar production patterns as $P$. acerina, $P$. tremellosa and $P$. hydnoides groups (Fig. 4c), and endoglucanase activities (Fig. 4e) were at the same levels in P. radiata, P. tremellosa and $P$. subserialis phylogroup cultures. Isolate-level differences among the species groups were also observed in hyphal growth rates on ME agar (Additional file 5: Figure S4f).

This study utilized generalized estimating equations (GEE) method to analyze differences resulting from enzyme activity values of the samples taken and measured at sequential time points. When the complete cultivation period ( $21 \mathrm{~d}$ ) was studied, statistically significant differences in production of lignocellulose-converting oxidoreductases and cellulolytic enzyme activities were detected between the phylogroups (Additional file 6: Table S2). In the statistical calculations, time and species group were the explanatory variables, and also their interaction was statistically significant. When fitted values of enzyme activities of each phylogroup were plotted, the high variation of laccase activity production levels between the phylogroups was observed (Fig. 3). $P$. radiata group produced the highest activities of laccase and $\mathrm{MnP}$ during the cultivation period. The second best producer of laccase activity were the $P$. tremellosa and $P$. hydnoides phylogroups which produced increasing amounts of laccase activity within the course of the cultivation. Together with the $P$. radiata phylogroup, the $P$. acerina and $P$. tremellosa groups produced higher amounts of $\mathrm{MnP}$ activity compared to the other phylogroups. Fitted values of enzyme activities of each phylogroup showed moderate production of cellulolytic activities. The phylogenetically most distant and incoherent group, the P. subserialis group, produced the highest $\mathrm{CBH}$ and $\beta$-glucosidase activities when compared to the other Phlebia phylogroups.

\section{$\mathrm{pH}$ values and culture acidity}

The $\mathrm{pH}$ values of the culture fluids remained stable during the $21 \mathrm{~d}$ cultivation period for most of the fungal isolates (Fig. 4f). However, a few of the $P$. radiata isolates (FBCC43, FBCC149, and FBCC194) and P. acerina isolate $\mathrm{FBCC} 4$ apparently acidified their cultures leading to final $\mathrm{pH}$ values below 4.0, which suggests active production of organic acids. On the contrary, final $\mathrm{pH}$ values in the cultures of $P$. tremellosa isolates FBCC446 and FBCC82, P. ochraceofulva isolates FBCC360 and FBCC295, $P$. centrifuga isolate FBCC359, and P. subserialis isolate FBCC426 increased to $\mathrm{pH}$ values over 6 (pH 6.3-6.9).

\section{Enzyme phenotype clusters}

To further visualize and compare the plant-biomass degrading enzyme production profiles as combinations of the periodical enzyme activity values of the fungal isolates, a double hierarchical clustering calculation method was adopted. Similarities of enzyme activities in the semi-solid milled spruce cultures for each sampling day were calculated to create the data matrix. The normalized enzyme activity values on cultivation day 14 were selected for presentation (Fig. 5).

According to the normalized enzyme activity profiles at this time point, isolates of Phlebia demonstrated three enzyme phenotype clusters (Fig. 5). Cluster $C$ contained most of the isolates, including isolates of $P$. radiata and $P$. acerina, and this cluster demonstrated production of both laccase and MnP activities. Cluster B showed high endoglucanase activities and contained sixteen isolates. In Cluster A, enzyme activity production was more scattered but included the highest production of cellulosedegrading $\mathrm{CBH}$ activities. Overall, clustering analysis pinpointed two enzyme production patterns: Phlebia isolates producing high oxidoreductase (laccase and $\mathrm{MnP})$ activities, and isolates showing high activities of cellulose-degrading enzymes $(\mathrm{CBH}$, endoglucanase, $\beta$ glucosidase).

\section{Discussion}

In this study, we report on the interdependence of fungal molecular systematics (genotyping) and extracellular enzyme activity profiles (enzyme phenotyping) for isolates of ten species of the largely unknown genus Phlebia and other representatives of the phlebioid clade of Polyporales. The 49 fungal isolates were subjected to multilocus gene phylogeny, and cultivated on semi-solid spruce wood medium to follow wood-decay enzyme activities for a three-week period.

Besides enzyme production profiling, our second attempt was to examine molecular systematics of the taxonomically incoherent genus Phlebia, and to more accurately position the type species ( $P$. radiata) in the 


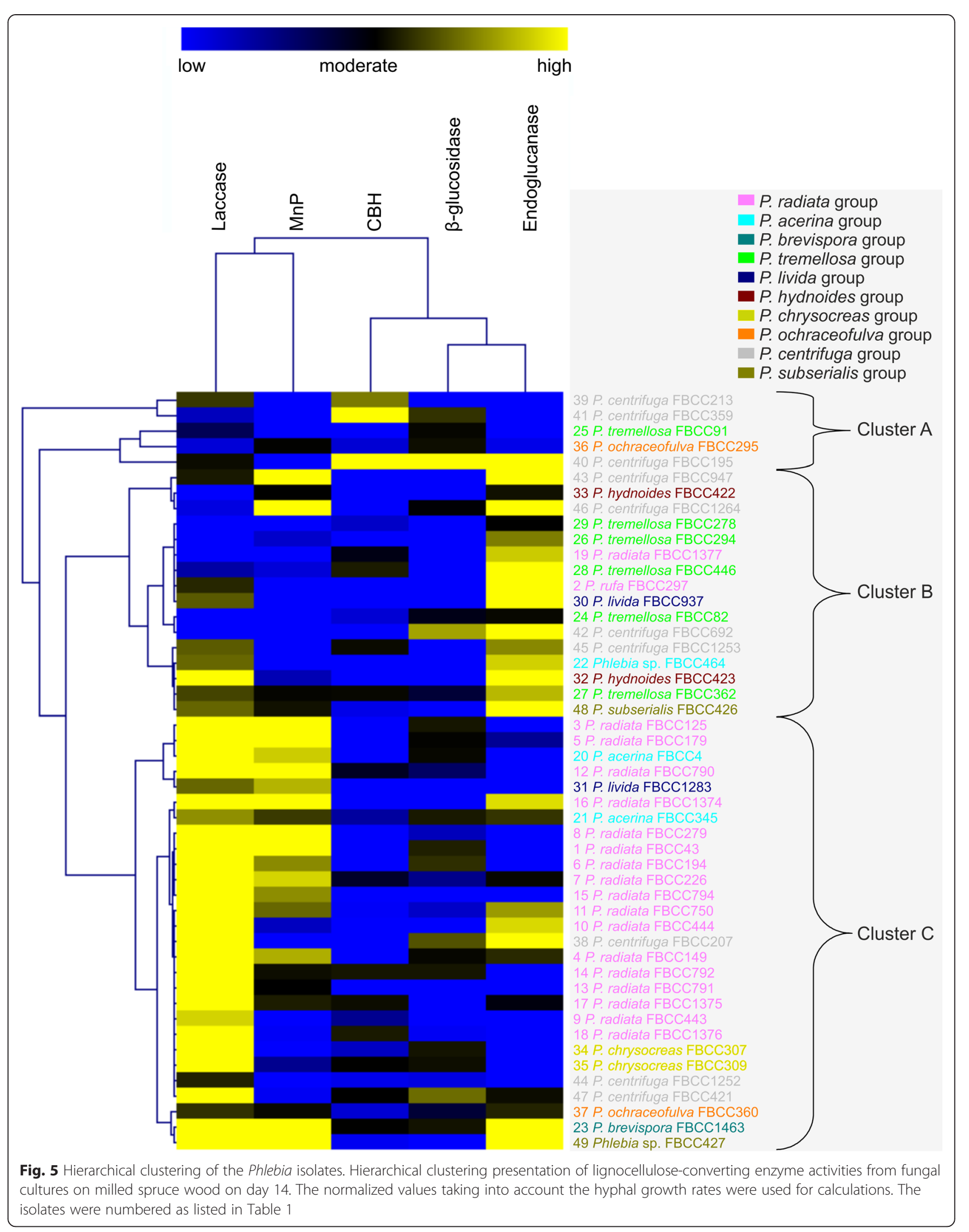


genus and phlebioid clade. The genus Phlebia has been proposed to be a set of unrelated taxa that have some shared morphological traits [47]. Our sequence-based phylogenetic study was also conducted in order to confirm taxonomic species-level identity of phlebioid and Phlebia isolates with previous history of principally morphology-based identification.

Several studies - both traditional and modern molecular systematics applying - have tried to resolve the taxonomy of the multiple genera positioned in the phlebioid clade of Polyporales, but so far without complete success [21, 22, 48-52]. The recent study on phanerochaetoid fungi increased this knowledge but showed the need for reference sequences for some of the species. Our study provided 152 new sequences, and the phylogenetic analyses, both multilocus alignment and single-gene phylogenetic analysis, produced phylograms which point out that fungi with taxon species name Phlebia are found in most of the currently recognized lineages of the phlebioid clade (order Polyporales, class Agaricomycetes) [21].

In our study, the barcode marker sequence [46] demonstrated its usefulness for concluding phylogenetic positioning of evolutionarily closely and more distantly related species of Phlebia. Although the ITS region is useful to resolve fungal phylogenetic relationships to certain extent, the importance of using other non-protein and protein-encoding genes to resolve the phylogenetic position of certain Phlebia species has been demonstrated $[47,49,50]$. For these reasons, we included three genes - rRNA LSU, and protein-encoding gapdh and $r p b 2$ - to improve the outcome of our molecular systematic and evolutionary analyses.

Species named as Phlebia can be found in other clades of Polyporales, for example the species P. bresadolae and $P$. queletii belong to the 'residual polyporoid clade' [21]. It has been described earlier that the Phlebia clade is not uniformly composed of only Phlebia species [20]. This study confirmed that the Phlebia clade includes also fungal isolates identified to the genera Ceriporiopsis, Scopuloides, Climacodon, Phlebiopsis, Ceriporia and Hydnophlebia. This demonstrates the difficulty to obtain a uniform phylogenetic analysis on Phlebia species. For that reason, extensive ITS phylogeny was used as a starting point for generating Phlebia, Phanerochaete and Phlebiopsis clades, wherein our isolates were positioned. After analyzing the Phlebia clade, our study confirmed the existence of the Phlebia sensu stricto [20]. According to our ITS analysis we propose that at least $P$. lindtneri, $P$. serialis and $P$. leptospermi should be added to this core group. It remains unclear, if $P$. centrifuga belongs to the core group since other phylogenetic analyses of this study and other studies on P. centrifuga $[20,49]$ are not supporting this positioning.
Species-level identity of most of our fungal isolates was confirmed by the four-gene and ITS sequence phylogeny analyses, and taxonomic re-positioning occurred only for a few Phlebia-named isolates. Two isolates (FBCC4, FBCC345) previously identified as $P$. radiata were re-classified to $P$. acerina due to their high ITS sequence identity (99.4-99.5 \%) to $P$. acerina isolates. Sampling of the reference ITS sequences of $P$. radiata, $P$. acerina and $P$. rufa taxons obtained from NCBI showed that some of these isolates were incorrectly named. Difficulty to identify and discriminate these three species by using traditional methods is not a surprise since $P$. rufa, $P$. acerina and $P$. radiata are very similar in their basidiocarp (basidiomal) and hymenial macro-structure and micro-morphology [25], thus also supporting their genetic similarity and evolutionary close speciation.

P. chrysocreas isolates of this study (FBCC307, FBCC 309) were separated from the four reference $P$. chrysocreas isolates according to ITS sequence phylogeny. Four reference sequence isolates without specieslevel identity (named as Phlebia sp.) fall in between this rather scattered branch. P. ochraceofulva isolates (FBCC 295 and FBCC 360) produced a separated lineage without reference sequences. Their identity is problematic to confirm without more reference taxons.

Another peculiarity is the positioning of the isolate $P$. subserialis $\mathrm{FBCC} 426$ in our phylogenetic analyses, which supported clustering of the isolate far from the Phlebia clade to the Phanerochaete clade. Different taxonomic positioning of isolates of $P$. subserialis has been observed in earlier studies [21, 47, 49-51,53]. According to our ITS phylogeny, there is a Phlebia subserialis lineage (number 1) in the Phlebia clade and a second lineage in the Phanerochaete clade (number 2). Recently, a third $P$. subserialis lineage has been demonstrated in the Phlebia clade [20]. Six P. subserialis ITS sequences were positioned in the Phanerochaete clade, but they were separated into two lineages (Additional file 2: Figures S1a, S1b). The first lineage includes our isolate FBCC426. A provisional species name of Phanerochaete krikophora was given to the second lineage [20].

We cultivated the phlebioid isolates on semi-solid medium containing milled Norway spruce wood, which is a natural lignocellulose substrate for a multitude of Polyporales wood-decay species in the northern temperate and boreal forests. Most of the Phlebia species prefer angiosperm wood for growth but may also colonize dead gymnosperm wood $[25,48]$. For instance $P$. centrifuga is usually observed as a saprotroph of Norway spruce [54]. So far, production and activities of wood-decay enzymes has been reported only for a few species of the phlebioid clade. In our study, the wood-containing medium supported production of lignin-modifying oxidoreductase and CAZyme activities in species of Phlebia. 
In general, moderate levels of cellulolytic endoglucanase activity were produced by all phlebioid isolates, and the highest activities were measured after two weeks of growth. Production of low endoglucanase activities on wood cultures by $P$. radiata and $P$. tremellosa isolates was demonstrated earlier [55], and negligible amounts of other cellulolytic activities have been observed for $P$. radiata cultures on lignocellulose substrates [26]. The type species $P$. radiata produces several cellulolytic enzymes, including $\beta$-1,4-endoglucanase, exo- $\beta$-1,4-glucanase, aryl- $\beta$-1,4-glucosidase, and $\beta$-1,4-glucosidase [56], hemicellulolytic enzymes, including $\beta$-xylosidase and endo-1,4- $\beta$-xylanase [57], and debranching enzymes, such as $\alpha$-glucuronidase and $\alpha$-galactosidase, which may cleave the glucosyl side-chains of hemicelluloses and pectin $[58,59]$. In this respect, it was expected that production of a wide array of CAZymes acting on wood polysaccharides would be as general as in P. radiata at least among the Phlebia sensu stricto species. The measured CAZyme activities were reasonably coherent within the species phylogroups, and the few observed differences between fungal isolates (intraspecies variation) may be a consequence of differences in the hyphal growth rates of the isolates.

According to enzyme activity production profiling, $P$. subserialis isolate (FBCC426) and most of the isolates of $P$. acerina and $P$. radiata clustered differently in the double hierarchical clustering calculation analysis. Also statistical analyses showed that the $P$. subserialis phylogroup produced higher cellulolytic enzyme $(\mathrm{CBH}$ and $\beta$-glucosidase) activities during the cultivation period compared to species that were included in the Phlebia sensu stricto. Phenotype similarity of $P$. subserialis to the genus Phanerochaete is well supported in this context, since Phanerochaete species (P. chrysosporium, P. carnosa, $P$. sordida) are well known producers of cellulolytic enzymes, with several CAZymes and respective genes characterized [60-62].

Considering the lignin-modifying oxidoreductases, our study reveals that there are significant differences in production of laccase activities among the Phlebia species groups. Production of laccase activity was one of the features clearly distinguishing between the enzyme phenotype groups. This is rather surprising since production of laccase has classically categorised wooddecay fungi as white rot and lignin-modifying species [63]. However, in line with the accumulating genomic data and comparative genomics on Basidiomycota and Polyporales species, the role of laccase in decomposition of wood lignin has been questioned [3, 64]. Instead, it is more evident that secreted class II heme peroxidases and in particular, various MnPs are necessary for lignin degradation and white rot type of wood decay $[1,2]$.
In this respect, it was assumed that all phlebioid isolates studied could actively produce $\mathrm{MnP}$ when growing on spruce wood. Convincingly, MnP activities were either at moderate steady levels throughout the cultivation period, or a pattern of cyclic production (MnP activity peaking on 10th and 17th cultivation day) was observed for closely related $P$. radiata, $P$. acerina and $P$. tremellosa strains. Cyclic production of $\mathrm{MnP}$ has been reported for $P$. radiata isolate $\mathrm{FBCC} 43$ on milled alder wood under similar cultivation conditions [28]. Furthermore, high MnP activities as well as protein properties for $\mathrm{MnP}$ enzymes (long- and short-MnPs) and isoenzymes have been reported for several Phlebia species ( $P$. radiata, $P$. tremellosa, $P$. brevispora, $P$. floridensis, $P$. subserialis, Phlebia sp. MG60, and Phlebia sp. b19) [8, 42, 43, 65-67], and divergent mnp genes have been cloned from e.g. P. radiata [27].

Surprisingly, no lignin peroxidase (LiP) activity was detected in the spruce wood cultures of any of the phlebioid isolates studied, although isolates of $P$. radiata, $P$. tremellosa, P. floridensis, P. brevispora and P. ochraceofulva produced LiP enzymes under variant culture conditions and in cultures including solid lignocellulose supplements $[8,28,41,42,67]$. For $P$. radiata, LiP activity has been reported even on similar semi-solid cultures but supplemented with alder sawdust [28, 30], and three LiP-encoding genes have been cloned and characterized in this species [37]. Partial lip gene sequences were amplified from isolates of $P$. tremellosa and $P$. chrysocreas [68]. In several previous studies $[38,66,69]$ the authors have discussed that LiP activities may not be detectable due to the presence of coloured, apparently phenolic compounds, which are dissolved in the fungal cultures from the wood and plant biomass substrates. These type of compounds may have masked LiP activities also in our study.

Our ITS sequence phylogeny analysis was in agreement with the recent extensive ITS phylogeny study on taxa of Phanerochaete and related genera [20]. The protein-encoding gene (gapdh and rpb2) regions, however, were somewhat less successful in supporting evolutionary positioning of our set of Phlebia isolates. The gapdh primers designed and applied in this study resulted in a higher frequency of PCR amplification than obtained with rpb2 primers. Accordingly, gapdh intron positioning was one of the genotyping features most conserved among the Phlebia sensu stricto species. Presence of a unique second intron in gapdh genes of $P$. centrifuga isolates differentiated this species from Phlebia sensu stricto. One challenge in using the gapdh region for molecular systematics and phylogenetic analyses is yet the lack of reference sequences in nucleotide sequence databases. For this reason, current use of primers targeted to ITS sequences and rRNA encoding genes 
together with carefully selected conserved proteinencoding genes promotes coherency for taxonomic comparison and fungal systematics.

\section{Conclusions}

Our study on the polyphyletic genus Phlebia infers that the fungal phylogroups showed significant differences in lignocellulose-converting enzyme phenotypes according to generalized estimation statistical analysis. These results may reflect different efficiencies of the enzymeproduction profiles of Phlebia species in their natural habitats, and predict their life-style differences on strategies to degrade various types of wood and lignocellulose. Knowledge of the taxonomy and physiological versatility of genus Phlebia has a great importance for more applicative studies on fungal enzyme production and bioconversion abilities. Our study is the first using such approach of combined molecular genotyping and enzyme activity profiling, and may thus be an example for similar research for systematically unknown or biochemically less studied wood-decay fungi, and aid in characterizing new fungal species and isolates.

\section{Methods}

\section{Fungal isolates}

The fungal isolates (Table 1) were living pure cultures deposited in the University of Helsinki Fungal Biotechnology Culture Collection (FBCC, fbcc@helsinki.fi), of the Division of Microbiology and Biotechnology, Department of Food and Environmental Sciences.

\section{Cultivation of the fungal isolates}

Fungal isolates (Table 1) were maintained on $2 \%(\mathrm{w} / \mathrm{v})$ malt-extract (Biokar Diagnostics, France) agar (2\% w/v agar-agar, Biokar Diagnostics, France) (MEA) plates at room temperature. For extraction of DNA, fungal isolates were cultivated on $2 \%$ MEA plates for 14 days at $28{ }^{\circ} \mathrm{C}$. For the determination of hyphal growth rates, one mycelium agar plug (7 $\mathrm{mm}$ in diameter) was inoculated in the center of each $2 \%$ MEA plate and cultivated for 14 days at $28{ }^{\circ} \mathrm{C}$ - except in the case of the fungal isolates FBCC297, FBCC464, FBCC1283, FBCC422, FBCC423, FBCC359 and FBCC421, which were cultivated at $22{ }^{\circ} \mathrm{C}$. For enzyme activity production, Phlebia spp. strains were cultivated as semi-solid liquid cultures in three parallel flasks containing $100 \mathrm{ml}$ of lownitrogen asparagine-succinate medium, $\mathrm{pH} 4.5$ [31, 35], without glucose but supplemented with $1 \mathrm{~g}$ (dry weight) of milled Norway spruce (Picea abies) wood as the sole carbon source. The semi-solid cultures were inoculated with four mycelial agar plugs (7 $\mathrm{mm}$ in diameter) from 7-14 days grown MEA plates, and incubated for 21 days at $28{ }^{\circ} \mathrm{C}$ in the dark as stationary cultures.

\section{DNA extraction}

Pieces of mycelia were disrupted with acid-washed and sterilized glass beads (1-2 mm) in sterile plastic cryotubes using FastPrep ${ }^{\oplus}$-24 Instrument (M.P. Biomedicals, USA). DNA was extracted by using CTAB buffer and purified as previously described [27]. Amount and quality of total DNA was determined with NanoDrop 1000 Spectrophotometer (Thermo Scientific, Germany).

\section{PCR amplification}

Complete nuclear rDNA ITS region $(\mathrm{ITS} 1+5.8 \mathrm{~S}+$ ITS2), part (1361-1419 bp) of the large rRNA subunit (LSU) coding region, partial (505-636 bp) sequence of the glyceraldehyde phosphate dehydrogenase encoding gene (gapdh), and a ca. $1097 \mathrm{bp}$ region of the $140 \mathrm{kDa}$ size subunit of the nuclear RNA polymerase II encoding gene $(r p b 2)$ were PCR amplified by using genomic DNA as template. The complete ITS region was amplified with ITS1 and ITS4 primers [70], the $5^{\prime}$ region of the LSU with 5.8sr and LR7 primers [71], and the partial $r p b 2$ region with $7 \mathrm{cf}$ and $11 \mathrm{bR}$ primers [72]. Primers were designed to amplify the partial gapdh region from Phlebia isolates (fw: 5' -ATG GTC TAC ATG TTC AAG TAC GAC-3'; rev: 5' -TCG ACG AGG GGA TGA TGT T -3'). PCR reactions were conducted with Dynazyme II or Phusion Hot Start DNA polymerase (Finnzymes, Finland). PCR was performed as previously described [27, 73].

\section{Sequencing}

The amplified PCR products were either directly used as templates or cut out of the agarose gels and purified with GeneJET ${ }^{\mathrm{mm}}$ Gel Extraction Kit (Fermentas, Lithuania), and used for sequencing (Institute of Biotechnology, University of Helsinki, Finland, and Macrogen Ltd, Republic of Korea) with the initial PCR primer pairs.

\section{Sequence analyses}

Nucleotide sequences were edited and assembled with BioEdit software [74]. Regions of ITS1, 5.8S and ITS2 were identified with the ITS extractor software [75]. Introns were excluded manually from the proteinencoding gapdh sequences in all analyses. They were confirmed by recognizing the consensus exon/intron splice junction sequences present in reference genes. Reference sequences were obtained from NCBI GenBank (http://www.ncbi.nlm.nih.gov), especially the ITS sequences produced by Floudas and Hibbet [20], and JGI MycoCosm genome portal (http://genome.jgi.doe.gov/ programs/fungi/index.jsf, [76], Additional file 7: Table S3). All sequences were aligned using PRANK (http:// www.ebi.ac.uk/goldman-srv/webprank/) with the default settings [77]. The alignments were manually trimmed 
(overhangs were removed and gaps were corrected) prior to phylogenetic analyses.

After multiple alignment of each trimmed gene, ITS alignment comprising the regions ITS1, 5.8S and ITS2 of 481 DNA sequences from taxa of the phlebioid clade was created and subjected to maximum likelihood (ML) inference by using RAxML v. 7.2.8 (http://phylobench. vital-it.ch/raxml-bb/, [78]). The best-scoring ML tree was searched and the bootstrap analysis was run under the GTRCAT model, using 100 rapid bootstrap replicates. Trees were visualized with the Interactive Tree Of Life (iTOL) online tool [79] and CorelDRAW X3 software (Corel Corporation, Canada). The resulted ML tree helped to divide ITS sequences into four subsets. The ITS sequences of each subset were realigned separately using PRANK and the ML analyses were performed with the same parameters in each case. Multilocus phylogenetic analysis based on 5.8S (SSU) (158 nucleotides), and LSU (1421 nucleotides), gapdh (413 nucleotides) and rpb2 (913 nucleotides) gene coding regions were conducted from the aligned dataset of 62 combined nucleotide sequences containing 2905 positions, of which 810 were variable (including missing data). ITS1 and ITS2 sequences were omitted from the four-gene phylogeny since these were poorly aligned. ML analysis was performed for this alignment with RAxML with GTRCAT model of evolution. Node support was assessed with 100 rapid bootstrap replicates. Individual runs were also performed for each target sequence and for combined ribosomal (ITS + LSU) sequences and combined proteinencoding sequences (gapdh $+r p b 2)$. The ML analyses were performed with the same parameters in each case.

\section{Determination of enzyme activities}

Enzyme activities from samples collected on days 3, 7, $10,14,17,21$ and 28 after inoculation from three semisolid culture flasks were measured by using 96-well plates and Tecan Infinite M200 microplate reader spectrophotometer (Tecan, USA) for each fungal isolate. Reaction volume was $250 \mu \mathrm{l}$, and three parallel reactions were measured for each sample and each fungal culture flask.

Laccase activity was determined by following the oxidation of $1 \mathrm{mM}$ 2,6-dimethoxyphenol (2,6-DMP, Aldrich, Germany) at $476 \mathrm{~nm}$ in $50 \mathrm{mM} \mathrm{Na-malonate}$ buffer (pH 4.5) at $25{ }^{\circ} \mathrm{C}[28,80] . \mathrm{MnP}$ activity was assayed by detecting the formation of $\mathrm{Mn}^{3+}$-malonate complex at $270 \mathrm{~nm}$ in $50 \mathrm{mM} \mathrm{Na-malonate} \mathrm{buffer}$ (pH 4.5) at $25^{\circ} \mathrm{C}$ [81].

Cellulase (cellobiohydrolase I, $\beta$-glucosidase and endo- $\beta$-1,4-glucanase) reactions were performed in $50 \mathrm{mM} \mathrm{Na}$-citrate buffer (pH 5) at $45{ }^{\circ} \mathrm{C}$ [82]. Cellobiohydrolase (CBHI) activity was measured by using 4methylumbelliferyl- $\beta$-D-lactoside (MULac, Biokemis,
Russia) as substrate. $\beta$-glucosidase activity was assayed by quantification of $p$-nitrophenol released from $1 \mathrm{mM}$ 4-nitrophenyl $\beta$-D-glucopyranoside (Applied Chemical Laboratories, USA) at $400 \mathrm{~nm}$. Endo- $\beta$-1,4-glucanase activity was determined with $1 \%$ (wt/vol) hydroxyethyl cellulose (HEC, Sigma, USA) as a substrate. Reducing sugars were measured with dinitrosalisylic acid (DNS) at $540 \mathrm{~nm}$ [82].

For calculation of the hyphal growth rate, mean data points (measured from three parallel MEA plates) were selected from the linear growth phase. This was presented as $\mathrm{cm} \mathrm{d}^{-1}$. Enzyme activity values on cultivation day 14 were divided by this value to obtain the 'normalized' enzyme activity values.

\section{Statistical analyses}

The linear models and the method of generalized estimating equations (GEE) were used to analyze differences in the set of enzyme activities between the Phlebia phylogroups. The phylogroups were determined by the multigene sequence similarity and evolutionary analysis. In each generalized linear model, time and group were explanatory variables and their interaction terms were also included in all models. The enzyme activities were assumed to follow the Tweedie distribution with link function chosen to be the log link. The working correlation matrix of within-subject repeated measurements was assumed to have a first-order autoregressive structure in each model. In estimation, the index parameter of the Tweedie distribution was first estimated by using the $\mathrm{R}$ software 3.1.1 (R Core Team, 2014) with the tweedie package. Then the GEE procedure was performed by using IBM SPSS Statistics 22, release 22.0.0.0 (IBM Corporation, USA). Significance level of $5 \%$ was used in all analyses.

To visualize normalized enzyme activity profiles of the 49 Phlebia isolates after 14 days of growth on semi-solid milled spruce medium, hierarchical clustering of the enzyme activities was performed by generating a Pearson correlation matrix with Multiexperiment Viewer (MeV) [83].

\section{Availability of supporting data}

The data sets supporting the results of this article are included within the article and its additional files. All nucleotide sequences were deposited in EMBL-EBI European Nucleotide Archive (ENA) under accession numbers presented in Additional file 1: Table S1 [EMBL: LN610995-LN611135 and LN651202-LN651212].

\section{Additional files}

Additional file 1: Table S1. Morphological and sequence based identification of isolates and sequenced specimens used in this study. (PDF $152 \mathrm{~kb}$ ) 
Additional file 2: Figure S1. Maximum likelihood analysis of ITS sequences of (a) Phanerochaete and (b) Phlebiopsis lineages of the phlebioid clade. Description: Bootstrap values (100 replications) higher than $50 \%$ are indicated for the nodes. Fungi of this study (shaded in blue) are compared with related taxons with sequences retrieved from NCBI (http://www.ncbi.nlm.nih.gov/) database. Quotation marks represent uncertain identification or provisional names [20]. Scale bar represents 0.01 nucleotide substitutions per position. (TIFF $4093 \mathrm{~kb}$ )

Additional file 3: Figure S2. Maximum likelihood tree of Phlebia isolates and related species. Description: Partial nucleotide sequences from (a) rRNAencoding genes (ITS1-5.8S-ITS2, LSU) and (b) two protein-encoding genes (gapdh, rpb2) were concatenated for alignment, and the phylogenetic analysis was performed using RAxML v. 7.2.8. and 100x bootstrapping for the nodes. For comparison, sequences from JGI MycoCosm database [76] and $\mathrm{NCBI}$ were retrieved. Species names are followed by isolate culture collection identifiers or sequence accessions. Bootstrap values higher than $50 \%$ are indicated for the nodes. Scale bar represents 0.01 nucleotide substitutions per position. (TIFF $3310 \mathrm{~kb}$ )

Additional file 4: Figure S3. Phylogenetic trees of phlebioid isolates from maximum likelihood analyses of individual gene datasets. Description: Bootstrap values (100 replications) higher than $50 \%$ are indicated for the nodes. Species names are followed by culture collection identifiers. For comparison, sequences from JGI MycoCosm database [76] were retrieved. Scale bar represents 0.01 nucleotide substitutions per position. (TIFF 6079 kb)

Additional file 5: Figure S4. Normalized enzyme activities of culture liquids and hyphal growth rates of Phlebia isolates. Description: Normalized extracellular (a) laccase (b) MnP (c) $\mathrm{CBH}$ (d) $\beta$-glucosidase and (e) endoglucanase activities on day 14 in semi-solid milled spruce cultures of Phlebia isolates. Error bars represent standard deviation of the mean activity value from two parallel cultivations. (f) Hyphal growth rates from three parallel MEA plates. Mean value for each isolate is presented. Error bars represent variance of the growth rates. The isolates were numbered as listed in Table 1. (TIFF $1427 \mathrm{~kb}$ )

Additional file 6: Table S2. Statistical tests of model effects and estimates of index parameter in Tweedie distribution. (PDF 155 kb)

Additional file 7: Table S3. Accessions for nucleotide and protein-encoding gene model sequences used for comparison in the four-gene phylogenetic analyses. Description: All the sequences were retrieved from JGI MycoCosm database [76] with minor exception: ${ }^{a}$ from NCBI http://www.ncbi.nlm.nih.gov/. (PDF 13 kb)

\section{Abbreviations}

CAZymes: carbohydrate active enzymes; $\mathrm{CBH}$ : cellobiohydrolase; FBCC: University of Helsinki Fungal Biotechnology Culture Collection; gapdh: gene encoding for glyceraldehyde phosphate dehydrogenase; GEE: generalized estimating equations; ITS: internal transcribed spacer; LiP: lignin peroxidase; LSU: large rRNA subunit; MEA: malt extract agar; ML: maximum likelihood; MnP: manganese peroxidase; rpb2: gene encoding for a nuclear RNA polymerase II subunit; SSU: small rRNA subunit.

\section{Competing interests}

The authors declare that they have no competing interests.

\section{Authors' contributions}

JK carried out the experiments, analyzed the data and wrote the manuscript. MRM participated in the design and coordination of the study and contributed to the writing of the manuscript. J planned and participated in the statistical analyses. 10 planned and participated in the bioinformatic analyses. TL conceived the study, participated in its design and contributed to the writing of the manuscript. All authors read and approved the final manuscript.

\section{Acknowledgements}

The study was supported by the Academy of Finland Ox-Red research project (grant 138331 to TL). The Microbiology and Biotechnology Doctoral Programme of the University of Helsinki is thanked for the doctoral study position for JK. The authors want to thank the editor and the reviewers for valuable comments on our results and manuscript. Mr Pekka Oivanen is acknowledged for information on the fungal isolates.

\section{Author details}

'Department of Food and Environmental Sciences, Division of Microbiology and Biotechnology, University of Helsinki, Viikki Biocenter 1, P.O.B. 56, FIN-00014 Helsinki, Finland. ${ }^{2}$ Department of Forest Sciences, University of Helsinki, Helsinki, Finland.

Received: 20 January 2015 Accepted: 25 September 2015 Published online: 19 October 2015

\section{References}

1. Floudas D, Binder M, Riley R, Barry K, Blanchette RA, Henrissat B, et al. The Paleozoic origin of enzymatic lignin decomposition reconstructed from 31 fungal genomes. Science. 2012;336:1715-9.

2. Ruiz-Dueñas FJ, Lundell T, Floudas D, Nagy LG, Barrasa JM, Hibbett DS, et al. Lignin-degrading peroxidases in Polyporales: an evolutionary survey based on 10 sequenced genomes. Mycologia. 2013;105:1428-44.

3. Lundell TK, Mäkelä MR, de Vries RP, Hildén KS. Genomics, lifestyles and future prospects of wood-decay and litter-decomposing basidiomycota. In: Francis MM, editor. Advances in Botanical Research, Vol 70, Fungi. London: Academic; 2014. p. 329-70.

4. Hori C, Gaskell J, Igarashi K, Samejima M, Hibbett D, Henrissat B, et al. Genomewide analysis of polysaccharides degrading enzymes in 11 whiteand brown-rot Polyporales provides insight into mechanisms of wood decay. Mycologia. 2013;105:1412-27.

5. Riley R, Salamov AA, Brown DW, Nagy LG, Floudas D, Held BW, et al. Extensive sampling of basidiomycete genomes demonstrates inadequacy of the white-rot/brown-rot paradigm for wood decay fungi. Proc Natl Acad Sci U S A. 2014;111:9923-8.

6. Kamei I, Hirota Y, Mori T, Hirai H, Meguro S, Kondo R. Direct ethanol production from cellulosic materials by the hypersaline-tolerant white-rot fungus Phlebia sp. MG-60. Bioresour Technol. 2012;112:137-42.

7. Fatehi $P$, Ates $S, N i$ Y. Fungal pretreatment of wheat straw and its effect on the soda-AQ pulps. Nord Pulp Pap Res J. 2009;24:193-8.

8. Arora DS, Gill PK. Production of ligninolytic enzymes by Phlebia floridensis. World J Microbiol Biotechnol. 2005;21:1021-8.

9. Campoy S, Alvarez-Rodríguez ML, Recio E, Rumbero A, Coque J-JR. Biodegradation of 2,4,6-TCA by the white-rot fungus Phlebia radiata is initiated by a phase I (O-demethylation)-phase II (O-conjugation) reactions system: implications for the chlorine cycle. Environ Microbiol. 2009;11:99-110.

10. Kamei I, Suhara H, Kondo R. Phylogenetical approach to isolation of whiterot fungi capable of degrading polychlorinated dibenzo-p-dioxin. Appl Microbiol Biotechnol. 2005;69:358-66.

11. Xiao P, Mori T, Kamei I, Kiyota H, Takagi K, Kondo R. Novel metabolic pathways of organochlorine pesticides dieldrin and aldrin by the white rot fungi of the genus Phlebia. Chemosphere. 2011;85:218-24.

12. Xu G, Wang J. Biodegradation of decabromodiphenyl ether (BDE-209) by white-rot fungus Phlebia lindtneri. Chemosphere. 2014;110:70-7.

13. Mori T, Kitano S, Kondo R. Biodegradation of chloronaphthalenes and polycyclic aromatic hydrocarbons by the white-rot fungus Phlebia lindtneri. Appl Microbiol Biotechnol. 2003;61:380-3.

14. Cho NS, Hatakka Al, Rogalski J, Cho HY, Ohga S. Directional degradation of lignocellulose by Phlebia radiata. J Fac Agric Kyushu Univ. 2009;54:73-80

15. Schüffler A, Wollinsky B, Anke T, Liermann JC, Opatz T. Isolactarane and sterpurane sesquiterpenoids from the basidiomycete Phlebia uda. J Nat Prod. 2012;75:1405-8.

16. Hibbett DS, Binder M, Bischoff JF, Blackwell M, Cannon PF, Eriksson OE, et al. A higher-level phylogenetic classification of the Fungi. Mycol Res. 2007;111:509-47.

17. Miettinen O, Larsson E, Sjökvist E, Larsson K-H. Comprehensive taxon sampling reveals unaccounted diversity and morphological plasticity in a group of dimitic polypores (Polyporales, Basidiomycota). Cladistics. 2012;28:251-70.

18. Binder M, Hibbett DS, Larsson $\mathrm{K}-\mathrm{H}$, Larsson $\mathrm{E}$, Langer $\mathrm{E}$, Langer $\mathrm{G}$. The phylogenetic distribution of resupinate forms across the major clades of mushroom-forming fungi (Homobasidiomycetes). Syst Biodivers. 2005;3:113-57. 
19. McLaughlin DJ, Hibbett DS, Lutzoni F, Spatafora JW, Vilgalys R. The search for the fungal tree of life. Trends Microbiol. 2009;17:488-97.

20. Floudas D, Hibbett DS. Revisiting the taxonomy of Phanerochaete (Polyporales, Basidiomycota) using a four gene dataset and extensive ITS sampling. Fungal Biol. 2015;119:679-719.

21. Binder M, Justo A, Riley R, Salamov A, Lopez-Giraldez F, Sjökvist E, et al. Phylogenetic and phylogenomic overview of the Polyporales. Mycologia. 2013;105:1350-73.

22. Moreno G, Blanco M-N, Checa J, Platas G, Peláez F. Taxonomic and phylogenetic revision of three rare irpicoid species within the Meruliaceae. Mycol Prog. 2011;10:481-91.

23. Nakasone KK. Studies in Phlebia. Six species with teeth. Sydowia. 1997:49:49-79.

24. Nakasone KK, Burdsall HH. Merulius, a synonym of Phlebia. Mycotaxon. 1984;21:241-6.

25. Nakasone KK, Sytsma KJ. Biosystematic Studies on Phlebia acerina, P. rufa, and $P$. radiata in North America. Mycologia. 1993;85:996-1016.

26. Niku-Paavola M-L, Karhunen E, Kantelinen A, Viikari L, Lundell T, Hatakka A. The effect of culture conditions on the production of lignin modifying enzymes by the white-rot fungus Phlebia radiata. J Biotechnol. 1990;13:211-21.

27. Hildén K, Martinez AT, Hatakka A, Lundell T. The two manganese peroxidases Pr-MnP2 and Pr-MnP3 of Phlebia radiata, a lignin-degrading basidiomycete, are phylogenetically and structurally divergent. Fungal Genet Biol. 2005;42:403-19.

28. Mäkelä MR, Lundell T, Hatakka A, Hildén K. Effect of copper, nutrient nitrogen, and wood-supplement on the production of lignin-modifying enzymes by the white-rot fungus Phlebia radiata. Fungal Biol. 2013:117:62-70.

29. Salavirta H, Oksanen I, Kuuskeri J, Mäkelä M, Laine P, Paulin L, et al. Mitochondrial genome of Phlebia radiata is the second largest (156 kbp) among fungi and features signs of genome flexibility and recent recombination events. PLoS One. 2014;9:e97141.

30. Mäkelä MR, Hildén KS, Hakala TK, Hatakka A, Lundell TK. Expression and molecular properties of a new laccase of the white rot fungus Phlebia radiata grown on wood. Curr Genet. 2006;50:323-33.

31. Hatakka Al, Uusi-Rauva AK. Degradation of ${ }^{14} \mathrm{C}$-labelled poplar wood lignin by selected white-rot fungi. Appl Microbiol Biotechnol. 1983;17:235-42.

32. Hakala TK, Maijala P, Konn J, Hatakka A. Evaluation of novel wood-rotting polypores and corticioid fungi for the decay and biopulping of Norway spruce (Picea abies) wood. Enzyme Microb Technol. 2004;34:255-63.

33. Hofrichter M, Lundell T, Hatakka A. Conversion of milled pine wood by manganese peroxidase from Phlebia radiata. Appl Environ Microbiol. 2001;67:4588-93.

34. Lundell T, Leonowicz A, Rogalski J, Hatakka A. Formation and action of lignin-modifying enzymes in cultures of Phlebia radiata supplemented with veratric acid. Appl Environ Microbiol. 1990;56:2623-9.

35. Moilanen AM, Lundell T, Vares T, Hatakka A. Manganese and malonate are individual regulators for the production of lignin and manganese peroxidase isozymes and in the degradation of lignin by Phlebia radiata. Appl Microbiol Biotechnol. 1996;45:792-9.

36. Lundell T, Hatakka A. Participation of $\mathrm{Mn}(\mathrm{II})$ in the catalysis of laccase, manganese peroxidase and lignin peroxidase from Phlebia radiata. FEBS Lett. 1994;348:291-6.

37. Hildén KS, Mäkelä MR, Hakala TK, Hatakka A, Lundell T. Expression on wood, molecular cloning and characterization of three lignin peroxidase (LiP) encoding genes of the white rot fungus Phlebia radiata. Curr Genet. 2006:49:97-105.

38. Vares T, Kalsi M, Hatakka A. Lignin peroxidases, manganese peroxidases, and other ligninolytic enzymes produced by Phlebia radiata during solidstate fermentation of wheat straw. Appl Environ Microbiol. 1995:61:3515-20.

39. Sharma RK, Arora DS. Solid state degradation of paddy straw by Phlebia floridensis in the presence of different supplements for improving its nutritive status. Int Biodeterior Biodegradation. 2011;65:990-6.

40. Sulej J, Janusz G, Mazur A, Żuber K, Żebracka A, Rogalski J. Cellobiose dehydrogenase from the ligninolytic basidiomycete Phlebia lindtneri. Process Biochem. 2013:48:1715-23.

41. Vares T, Lundell TK, Hatakka Al. Production of multiple lignin peroxidases by the white-rot fungus Phlebia ochraceofulva. Enzyme Microb Technol. 1993;15:664-9.
42. Vares $T$, Niemenmaa $O$, Hatakka A. Secretion of ligninolytic enzymes and mineralization of ${ }^{14} \mathrm{C}$-ring-labelled synthetic lignin by three Phlebia tremellosa strains. Appl Environ Microbiol. 1994;60:569-75.

43. Kamei I, Daikoku C, Tsutsumi Y, Kondo R. Saline-dependent regulation of manganese peroxidase genes in the hypersaline-tolerant white rot fungus Phlebia sp. strain MG-60. Appl Environ Microbiol. 2008;74:2709-16.

44. Hofrichter M, Vares K, Scheibner K, Galkin S, Sipilä J, Hatakka A. Mineralization and solubilization of synthetic lignin by manganese peroxidases from Nematoloma frowardii and Phlebia radiata. J Biotechnol. 1999;67:217-28.

45. Arora DS, Sharma RK. Effect of different supplements on bioprocessing of wheat straw by Phlebia brevispora: changes in its chemical composition, in vitro digestibility and nutritional properties. Bioresour Technol. 2011;102:8085-91.

46. Schoch CL, Seifert KA, Huhndorf S, Robert V, Spouge JL, Levesque CA, et al. Nuclear ribosomal internal transcribed spacer (ITS) region as a universal DNA barcode marker for Fungi. Proc Natl Acad Sci U S A. 2012;109:6241-6.

47. De Koker TH, Nakasone KK, Haarhof J, Burdsall Jr HH, Janse BJH. Phylogenetic relationships of the genus Phanerochaete inferred from the internal transcribed spacer region. Mycol Res. 2003;107:1032-40.

48. Ghobad-Nejhad M, Hallenberg N. Multiple evidence for recognition of Phlebia tuberculata, a more widespread segregate of Phlebia livida (Polyporales, Basidiomycota). Mycol Prog. 2010;11:27-35.

49. Wu S-H, Nilsson HR, Chen C-T, Yu S-Y, Hallenberg N. The white-rotting genus Phanerochaete is polyphyletic and distributed throughout the phleboid clade of the Polyporales (Basidiomycota). Fungal Divers. 2010:42:107-18.

50. Greslebin A, Nakasone KK, Rajchenberg M. Rhizochaete, a new genus of phanerochaetoid fungi. Mycologia. 2004;96:260-71.

51. Parmasto $E$, Hallenberg N. A taxonomic study of phlebioid fungi (Basidiomycota). Nord J Bot. 2000;20:105-18.

52. Larsson K-H, Larsson E, Kõljalg U. High phylogenetic diversity among corticioid homobasidiomycetes. Mycol Res. 2004;108:983-1002.

53. Suhara H, Sakai K, Kondo R, Maekawa N, Kubayashi T. Identification of the basidiomycetous fungus isolated from butt rot of the Japanese cypress. Mycoscience. 2002:43:477-81.

54. Kotiranta H, Saarenoksa R, Kytövuori I. Aphyllophoroid fungi of Finland. A check-list with ecology, distribution, and threat categories. Norrlinia. 2009;19:1-223.

55. Ander P, Eriksson K-E. Selective degradation of wood components by whiterot fungi. Physiol Plant. 1977:41:239-48.

56. Rogalski J, Hatakka A, Wojtas-Wasilewska M, Leonowicz A. Cellulolytic enzymes of the ligninolytic white-rot fungus Phlebia radiata. Acta Biotechnol. 1993;13:41-5

57. Rogalski J, Oleszek M, Tokarzewska-Zadora J. Purification and characterization of two endo-1,4- $\beta$-xylanases and a $\beta$-xylosidase from Phlebia radiata. Acta Microbiol Pol. 2001;50:117-28.

58. Prendecka M, Szyjka K, Rogalski J. Purification and properties of a-galactosidase isosymes from Phlebia radiata. Acta Microbiol Pol. 2003;52:25-33.

59. Mierzwa M, Tokarzewska-Zadora J, Deptuła T, Rogalski J, Szczodrak J. Purification and characterization of an extracellular alpha-D-glucuronidase from Phlebia radiata. Prep Biochem Biotechnol. 2005;35:243-56.

60. Diorio L, Galati B, García MA, Papinutti L. Degradation of pruning wastes by Phanerochaete sordida growing in SSF: Ultrastructural, chemical, and enzymatic studies. Int Biodeterior Biodegradation. 2009;63:19-23.

61. Vanden Wymelenberg A, Gaskell J, Mozuch M, Kersten P, Sabat G, Martinez $D$, et al. Transcriptome and secretome analyses of Phanerochaete chrysosporium reveal complex patterns of gene expression. Appl Environ Microbiol. 2009;75:4058-68.

62. MacDonald J, Doering M, Canam T, Gong Y, Guttman DS, Campbell MM, et al. Transcriptomic responses of the softwood-degrading white-rot fungus Phanerochaete carnosa during growth on coniferous and deciduous wood. Appl Environ Microbiol. 2011;77:3211-8.

63. Hatakka A. Lignin-modifying enzymes from selected white-rot fungi: Production and role in lignin degradation. FEMS Microbiol Rev. 1994;13:125-35.

64. Lundell TK, Mäkelä MR, Hildén K. Lignin-modifying enzymes in filamentous basidiomycetes - ecological, functional and phylogenetic review. J Basic Microbiol. 2010;50:5-20.

65. Bonnarme $\mathrm{P}$, Jeffries TW. Mn(II) regulation of lignin peroxidases and manganese-dependent peroxidases from lignin-degrading white rot fungi. Appl Environ Microbiol. 1990;56:210-7. 
66. Hofrichter M, Vares T, Kalsi M, Galkin S, Fritsche W, Hatakka A. Production of manganese peroxidase and organic acids and mineralization of ${ }^{14} \mathrm{C}$-labelled lignin $\left({ }^{14} \mathrm{C}-\mathrm{DHP}\right)$ during solid-state fermentation of wheat straw with the white rot fungus Nematoloma frowardii. Appl Environ Microbiol. 1999;65:1864-70.

67. Perez J, Jeffries TW. Mineralization of ${ }^{14} \mathrm{C}$-ring-labeled synthetic lignin correlates with the production of lignin peroxidase, not of manganese peroxidase or laccase. Appl Environ Microbiol. 1990;56:1806-12.

68. Morgenstern I, Klopman S, Hibbett DS. Molecular evolution and diversity of lignin degrading heme peroxidases in the Agaricomycetes. J Mol Evol. 2008;66:243-57.

69. Orth $A B$, Royse DJ, Tien M. Ubiquity of lignin-degrading peroxidases among various wood-degrading fungi. Appl Environ Microbiol. 1993;59:4017-23.

70. White TJ, Bruns T, Lee S, Taylor JW. Amplification and direct sequencing of fungal ribosomal RNA genes for phylogenetics. In: Innis MA, Gelfand DH, Sninsky JJ, White TJ, editors. PCR Protocols: A Guide to Methods and Applications. New York: Academic Press Inc; 1990. p. 315-22.

71. Hopple JS, Vilgalys R. Phylogenetic relationships in the mushroom genus Coprinus and dark-spored allies based on sequence data from the nuclear gene coding for the large ribosomal subunit RNA: divergent domains, outgroups, and monophyly. Mol Phylogenet Evol. 1999;13:1-19.

72. Liu YJ, Whelen $\mathrm{S}$, Hall BD. Phylogenetic relationships among ascomycetes: evidence from an RNA polymerse II subunit. Mol Biol Evol. 1999;16:1799-808.

73. Mäkelä MR, Hildén K, Hatakka A, Lundell TK. Oxalate decarboxylase of the white-rot fungus Dichomitus squalens demonstrates a novel enzyme primary structure and non-induced expression on wood and in liquid cultures. Microbiology. 2009:155:2726-38.

74. Hall TA. BioEdit: a user-friendly biological sequence alignment editor and analysis program for Windows 95/98/NT. Nucleic Acids Symp Ser. 1999:41:95-8.

75. Nilsson RH, Veldre V, Hartmann M, Unterseher M, Amend A, Bergsten J, et al. An open source software package for automated extraction of ITS1 and ITS2 from fungal ITS sequences for use in high-throughput community assays and molecular ecology. Fungal Ecol. 2010;3:284-7.

76. Grigoriev IV, Nikitin R, Haridas S, Kuo A, Ohm R, Otillar R, et al. MycoCosm portal: gearing up for 1000 fungal genomes. Nucleic Acids Res. 2014;42:D699-704.

77. Löytynoja A, Goldman N. webPRANK: a phylogeny-aware multiple sequence aligner with interactive alignment browser. BMC Bioinformatics. 2010;11:579.

78. Stamatakis A, Hoover P, Rougemont J. A rapid bootstrap algorithm for the RAxML Web servers. Syst Biol. 2008;57:758-71.

79. Letunic I, Bork P. Interactive Tree Of Life (iTOL): an online tool for phylogenetic tree display and annotation. Bioinformatics. 2007;23:127-8.

80. Slomczynski D, Nakas JP, Tanenbaum SW. Production and characterization of laccase from Botrytis cinerea 61-34. Appl Environ Microbiol. 1995;61:907-12.

81. Wariishi H, Valli K, Gold MH. Manganese(II) oxidation by manganese peroxidase from the basidiomycete Phanerochaete chrysosporium. Kinetic mechanism and role of chelators. J Biol Chem. 1992;267:23688-95.

82. Rytioja J, Hildén K, Hatakka A, Mäkelä MR. Transcriptional analysis of selected cellulose-acting enzymes encoding genes of the white-rot fungus Dichomitus squalens on spruce wood and microcrystalline cellulose. Fungal Genet Biol. 2014;72:91-8.

83. Saeed Al, Sharov V, White J, Li J, Liang W, Bhagabati N, et al. TM4: a free, open-source system for microarray data management and analysis. Biotechniques. 2003:34:374-8.

\section{Submit your next manuscript to BioMed Central and take full advantage of:}

- Convenient online submission

- Thorough peer review

- No space constraints or color figure charges

- Immediate publication on acceptance

- Inclusion in PubMed, CAS, Scopus and Google Scholar

- Research which is freely available for redistribution

Submit your manuscript at www.biomedcentral.com/submit 